\title{
Examining the role of spatial skills and mathematics motivation on middle school mathematics achievement
}

\author{
Kinnari Atit ${ }^{1 *}$ D, Jason R. Power ${ }^{2}$, Norma Veurink ${ }^{3}$, David H. Uttal ${ }^{4}$, Sheryl Sorby ${ }^{5}$, Grace Panther ${ }^{6}$, Camille Msall ${ }^{4}$, \\ Logan Fiorella ${ }^{7}$ and Martha Carr ${ }^{{ }^{\wedge}}$
}

\begin{abstract}
Background: Spatial skills and mathematical ability have been repeatedly identified as critical for achievement in Science, Technology, Engineering, and Mathematics (STEM). Previous studies have identified correlations between spatial skills and mathematical achievement; however, questions remain regarding improvements in non-spatial areas associated with STEM achievement. The current study examined whether competency in spatial skills could be related to individuals' motivation for mathematics. Measures of spatial skills and mathematics motivation were completed by 1056 seventh grade students.
\end{abstract}

Results: Using hierarchical linear modeling, spatial skills and math motivation were examined relative to students' performance on a state standardized mathematics subtest. Results indicate that spatial skills and motivation interact to significantly predict students' mathematics performance.

Conclusions: These results suggest that spatial skills in combination with motivation play a significant role in middle school students' mathematics achievement.

Keywords: Spatial skills, Mathematics achievement, Motivation, Middle school

\section{Introduction}

Despite substantial efforts to increase achievement in science, technology, engineering, and mathematics (STEM) fields, children's STEM performance in the USA continues to lag behind their international counterparts (e.g., Organization for Economic Co-operation and Development, 2016), particularly in mathematics. Thus, much research aims to understand factors underlying students' mathematics performance (e.g., Pajares \& Graham, 1999; Verdine, Golinkoff, Hirsch-Pasek, \& Newcombe, 2017), including spatial skills (e.g., Casey, Nuttall, \& Pezaris, 2001) and motivation (Ramirez, Gunderson, Levine, \&

\footnotetext{
* Correspondence: kinnari.atit@ucr.edu

All contributing authors have been listed in reverse alphabetical order after the first and second authors.

Dr. Martha Carr sadly passed away in the summer of 2017.

'Graduate School of Education, University of California, Riverside, 1207 Sproul

Hall, Riverside, CA 92521, USA

Full list of author information is available at the end of the article
}

Beilock, 2013). However, scant attention has been paid to the potential interaction between these factors, and the effect of the interaction on students' educational outcomes. Social cognitive theory (Bandura, 2005, 2012) suggests that if an individual believes spatial skills are relevant to performance in mathematics, then spatial skills could also impact an individual's motivation for mathematics. To date, no studies have examined how spatial skills and motivational factors together predict middle school students' mathematics achievement.

Research has established that cognitive skills and motivation are closely related (e.g., Ashcraft \& Kirk, 2001) and together can help explain students' mathematics achievement. Much of this work has focused on understanding the relations between individuals' working memory capacity, mathematics anxiety, and mathematics performance. For instance, Beilock and colleagues have established that mathematics performance suffers in 
children and adults with high working memory capacity who also have high levels of mathematics anxiety, but this relationship is not true for individuals with low working memory capacity (Beilock \& Carr, 2005; Ramirez et al., 2013). Here, we aim to understand the nuances of how a set of cognitive skills important for mathematical reasoning, spatial skills (e.g., Casey, Nuttall, Pezaris, \& Benbow, 1995; Reuhkala, 2001), combine with students' motivation for learning mathematics, to predict middle school students' mathematics performance. Furthermore, building on prior research, we aim to examine whether the relationships between spatial skills, motivation, and mathematics performance differ for students demonstrating different levels of mathematics motivation and mathematics-relevant skillsets (i.e., spatial skills and mathematical skills).

\section{Spatial skills and mathematics}

Spatial skills enable us to mentally manipulate, organize, reason about, and make sense of spatial relationships in real and imagined spaces (e.g., Newcombe \& Shipley, 2015; Uttal et al., 2013). They are commonly used when completing everyday tasks such as assembling furniture or navigating from one location to another. Researchers have found that spatial skills are malleable and can be improved through experience and practice (Uttal et al., 2013).

Studies examining the relationship between spatial skills and mathematics achievement find that the two are significantly correlated for students at all educational levels (e.g., Casey et al., 1995; Delgado \& Prieto, 2004; Geer et al., 2019; Mix et al., 2016; Mix et al., 2017; Verdine et al., 2017). For example, visuospatial working memory relates to superior performance on counting tasks (Kyttala, Aunio, Lehto, Van Luit, \& Hautamaki, 2003) and number line estimation (Geary, Hoard, Byrd-Craven, Nugent, \& Numtee, 2007) in children. Mental rotation performance relates to mathematical reasoning skills in middle school students (Delgado \& Prieto, 2004; Lombardi, Casey, Pezaris, Shadmehr, \& Jong, 2019) and mathematical aptitude in undergraduates (Casey et al., 1995). Furthermore, spatial skills predict students' future mathematics learning (Casey, Lombardi, Pollock, Fineman, \& Pezaris, 2017) even after accounting for other skills, such as verbal skills and executive functioning (Verdine et al., 2017; Zhang et al., 2014).

In addition to the performance-based evidence of the relation between spatial skills and mathematical achievement, prior research suggests that a positive relation between spatial and mathematical thinking may be based on shared cognitive processes (Gunderson, Ramirez, Beilock, \& Levine, 2012; Mix \& Cheng, 2012). Number information is mentally represented in spatial formats (e.g., Mix \& Cheng, 2012; Mix, 2019). For example, Gunderson et al. (2012) found that quantitative magnitudes are represented in the mind spatially as a mental number line. Further evidence comes from brain imaging studies showing similar areas of brain activation when individuals process both spatial and numerical information (e.g., Hubbard, Piazza, Pinel, \& Dehaene, 2005). Lastly, successful interventions often focus on helping students translate mathematical symbols or problem statements into spatial representations, including number lines, diagrams, concrete models, or hand gestures (e.g., Uttal, Scudder, \& DeLoache, 1997).

In summary, spatial skills are related to mathematical learning and performance (e.g., Casey et al., 2001), and spatial skills are malleable and can be improved with experience and practice (Uttal et al., 2013). Therefore, understanding how additional factors, such as students' motivation for learning mathematics, interacts with spatial skills to predict mathematics performance is critical to understanding how to improve students' outcomes.

\section{Motivation and mathematics}

Middleton and Spanias (1999) define motivation as "the reasons individuals have for behaving in a given manner in a given situation" (p. 66). Motivation is part of one's goal structures, one's beliefs about what is important, and determines whether or not one will engage in a given activity (Ames, 1992). Research suggests that students' motivation and feelings towards mathematics influence their performance (Cleary \& Chen, 2009; Meyer \& Fennema, 1985; Middleton \& Spanias, 1999). Highly motivated students tend to find academic activities more meaningful and derive greater benefits from them (Brophy, 1988). Motivation is influenced by interactions between student characteristics, student behaviors, and the learning environment (Bandura, 2001, 2005, 2006). Learning is most effective when students engage in self-regulatory strategies that help monitor and control their cognition, motivation, and behavior (Schunk, 2001). Highly motivated students engage in more self-regulatory behaviors, such as participating in class, seeking advice, and studying independently (e.g., Leaper, Farkas, \& Brown, 2012).

Several studies have found that students' motivation for mathematics influences their mathematics achievement (e.g., Hembree, 1990; Pajares, 1996). As a result, researchers from varying schools of thought have proposed many theories and focused much research on trying to understand the role of motivation in facilitating or inhibiting students' mathematics achievement. For instance, research conducted from the behaviorist perspective indicates that success in mathematics is a powerful influence on the motivation to achieve (Chang \& Beilock, 2016). Students perceive success as reinforcing, and they will engage in mathematics if they expect to be successful. Additionally, students will tend to enjoy tasks for which they have a moderately high probability of success more than tasks for which the probability of success is near chance (Dickinson \& Butt, 1989; Power, Lynch, \& McGarr, 2020). 
Attribution theorists propose that how the outcomes of an activity are evaluated in relation to the individual's perception of his or her own contribution (i.e., ability and effort) and the contribution of the task demands (i.e., difficulty) influences learning behavior. Students in lower elementary grades are generally highly motivated to learn mathematics. They believe that they are capable and that working hard will enable them to succeed. Many first and second graders do not differentiate between effort and ability as causes of success in mathematics (Kloosterman, 1993). By the middle grades, many students begin to perceive mathematics to be a special subject in which smart students succeed and other students merely "get by" or fail. They begin to believe that success and failure are attributable to ability and that effort rarely results in a significant change in their patterns of success (Kloosterman \& Gorman, 1990). Studies have shown that when students attribute their successes to ability, they tend to succeed; when they attribute their failures to lack of ability, they tend to fail (Meyer \& Fennema, 1985; Wang, Shakeshaft, Schofield, \& Malanchini, 2018).

Relatedly, the expectancy value model (Eccles \& Wigfield, 1985, 1995; Wigfield \& Eccles, 2000), which has often been examined in adolescents (Andersen \& Ward, 2014; Berger \& Karabenick, 2011), asserts that expectancies for success and task value are proximal determinants of such outcomes as effort, choice, and persistence. Expectancy is represented by self-concept of ability and self-efficacy. The four components of value are (a) intrinsic interest, that is, the enjoyment gained from doing the task; (b) attainment value that captures the importance of doing well on the task; (c) utility, which is defined as how useful the task is for the student's future; and (d) cost, that is, the effort and lost opportunities for engagement in the activity (Eccles \& Wigfield, 1985, 1995; Wigfield \& Eccles, 2000). Researchers have found that the motivational factors encompassed within the model predict student behaviors promoting mathematics learning and achievement (e.g., Berger \& Karabenick, 2011), but that expectancy and value beliefs towards the domain of mathematics declines as the student progresses through their grade school education. The decline in expectancy and value beliefs in students towards the domain of mathematics generally begins around the middle school grade levels (Jacobs, Lanza, Osgood, Eccles, \& Wigfield, 2002; Wigfield, Eccles, Mac Iver, Reuman, \& Midgley, 1991).

Proponents of goal theory suggest that how people think about engaging in meaningful or meaningless activity in conjunction with their perceptions, interpretations of academic and social information, and patterns of self-regulation influence their learning behavior and outcomes. An individual with a mastery goal orientation values the improvement of skill or knowledge in a given domain and believes that success depends on working hard, attempting to understand the subject, and collaborating with others. An individual with an ego goal orientation values establishing superiority over others and believes that success depends on social comparison and assertion of superior ability (Duda \& Nicholls, 1992). Lastly, an individual who exhibits work avoidance does not value hard work and believes that success results from extraneous factors to studying, such as good behavior in class. An individual's goal orientation interacts with their intrinsic and extrinsic motivation and influences student behavior (Meece, Blumenfeld, \& Hoyle, 1988). Intrinsic motivation is the drive or desire of a student to engage in learning for the sake of learning. Students who are intrinsically motivated engage in academic tasks because they enjoy them and feel that it is important with respect to their self-images (Middleton, 1993). Extrinsically motivated students engage in academic tasks to obtain rewards (e.g., good grades, approval) or to avoid punishment (e.g., bad grades, disapproval) (Ames, 1992; Ames \& Archer, 1988). Students who possess mastery goals will positively mediate intrinsic motivation such that they will be more actively involved in a cognitive task. Students who possess ego goals are much less affected by their intrinsic motivation and show little to no changes in their cognitive engagement patterns (Middleton \& Spanias, 1999). Mastery goal orientation has been found consistently to predict mathematics achievement in students (e.g., Keys, Conley, Duncan, \& Domina, 2012), while ego and work avoidance orientations have not.

Other motivational factors that have been extensively studied in relation to mathematics achievement are mathematics anxiety and self-efficacy. Mathematics anxiety, "feelings of tension and anxiety that interfere with the manipulation of numbers and the solving of mathematical problems in a wide variety of ordinary life and academic situations" (Richardson \& Suinn, 1972, p.551), hinders mathematics achievement in both children and adults (e.g., Hembree, 1990; Lee, 2009). Showing the opposite effect, self-efficacy, the belief in one's ability to succeed (Pajares, 1996), has been found to be a significant positive predictor of mathematics achievement (e.g., Pajares \& Graham, 1999). Across skill levels, students with high selfefficacy in mathematics solve problems more accurately and show greater persistence on difficult items than students with low self-efficacy (Collins, 1982).

The existing research on motivation in mathematics highlights the interrelated and inter-dependent nature of motivational constructs, such as self-efficacy and mathematics anxiety (Lee, 2009), and intrinsic and extrinsic motivation (e.g., Ryan \& Deci, 2000), on student behavior and student outcomes. Furthermore, it highlights that an individual's mathematics motivation is influenced by multiple factors such as one's goal orientations, one's beliefs about what is important, and one's perceptions about their own contributions (e.g., Pintrich, 2000). Therefore, in this study, we chose to examine students' 
motivation for learning mathematics using a measure grounded in prominent theories of academic motivation and encompassing many of the motivational factors found to underlie students' desires to learn mathematics. For this measure, we adapted Glynn, Taasoobshirazi, and Brickman's (2007) Science Motivation Questionnaire (SMQ) to assess students' motivation for learning mathematics. Based on prior research on mathematics motivation and Glynn, Taasoobshirazi, and Brickman's (2009) definition of a student's motivation to learn science, we define motivation to learn mathematics as a student's drive or desire to engage in mathematical tasks and/or learn the mathematical domain.

The Mathematics Motivation Questionnaire (MMQ) is composed of items measuring the following six motivational constructs: intrinsically motivated math learning, extrinsically motivated math learning, relevance of math learning to personal goals, responsibility for learning math (i.e., selfdetermination), confidence in learning math (i.e., selfefficacy), and anxiety about math assessment (i.e., low math anxiety). All of these constructs individually, or in different combinations, by researchers embracing specific theoretical perspectives, have been found to influence students' mathematics learning behavior and mathematics outcomes (e.g., Berger \& Karabenick, 2011; Lee, 2009; Meyer \& Fennema, 1985). However, no research, to our knowledge, has crossed multiple theoretical boundaries ascribed by individual schools of thought and examined how motivation to learn mathematics, measured by all six of these constructs combined, are related to students' mathematics achievement.

\section{Spatial skills and motivation together may contribute to predicting mathematics performance}

Research shows that cognitive skills and motivation interact to influence behaviors and outcomes, including in mathematics (e.g., Ashcraft \& Kirk, 2001; Ramirez et al., 2013). Ganley and Vasilyeva (2011) found that cognitive and motivational factors together predict middle school students' mathematics achievement, though the patterns differed by gender. Spatial skills predicted mathematics performance in boys, but it was not a significant predictor in girls when confidence and mathematics anxiety were included in the model (Ganley \& Vasilyeva, 2011). Ferguson, Maloney, Fugelsang, and Risko (2015) found that individuals with high mathematics anxiety perform worse on spatial skills tests than individuals with low mathematics anxiety, indicating that spatial skills and mathematics anxiety may be fundamentally linked (Ferguson et al., 2015). To our knowledge, the present study is the first to examine how spatial skills and students' motivation to learn mathematics together predict middle school students' mathematics achievement.

We focus on middle school students because the middle grades appear to be a crucial time in developing student interest in STEM domains (Bulunuz \& Jarrett, 2010; Harmer
\& Columba, 2010). Students' middle school experiences often influence the scholastic pathways they will take in the future. More specifically, students' beliefs about whether they will pursue STEM careers in the future influence their later educational and occupational choices. For instance, eighth graders with expectations for a STEM related career were 3.4 times more likely to earn STEM baccalaureate degrees when compared to students without similar expectations (Tai, Liu, Maltese, \& Fan, 2006). For many students, the middle grades are when interest and competency beliefs in STEM subjects, such as mathematics, starts to decline (e.g., Jacobs et al., 2002; Wigfield et al., 1991). Thus, understanding how motivational factors combine with spatial skills to predict mathematics achievement at this specific time in development could shed light on how to bolster mathematics outcomes and, in turn, improve students' educational trajectories with regard to STEM jobs and occupations.

In this study, we first examined whether spatial skills and mathematics motivation individually predicted middle school students' mathematical achievement and whether these relations were moderated by gender as prior research has found that gender differences are apparent on many tests of spatial skills (e.g., Miller \& Halpern, 2014) and also on many motivational constructs relevant to mathematics learning during adolescence (Jacobs et al., 2002). Second, we investigated how students' spatial skills in conjunction with mathematics motivation predicted middle school students' mathematics achievement. Lastly, we examined whether the influence of spatial skills and mathematics motivation on student mathematics performance differed between students with low versus high levels of spatial skills. To ensure that the relations between spatial skills, mathematics motivation, and mathematics achievement are not solely driven by students' overall performance in school, we controlled for differences by controlling for students' science performance. As the relations between spatial skills and varying mathematical domains (e.g., geometry, algebra, trigonometry) are still unclear, we used performance on a state standardized test of mathematics as our measure of overall mathematics achievement.

\section{Method \\ Participants}

We examined data from 1056 7th grade students (530 males, 526 females) from the state of Michigan in the United States ${ }^{1}$. Students' average age was 12.12 years $($ minimum $=10$ years old, maximum $=14$ years old $)$. Students were from 26 different classrooms in 11

\footnotetext{
${ }^{1}$ The analyses presented here are from data collected as part of a larger longitudinal study. In the larger study, 3061 7th grade students from 7 different states participated. Because standardized tests differ between states and are not nationally normed (e.g., Stansfield, 2011), here, we only examined data on participants who completed all of the relevant measures from the state of Michigan, the state with the largest number of participants.
} 
schools and were predominantly of White/Non-Hispanic origin (91.4\% White/Non-Hispanic, 2.5\% Black/African American, 1.7\% American Indian/Alaskan Native, 1\% Asian/Asian American, $1.5 \%$ Hispanic/Hispanic American, and 2.0\% multiracial). Prior to students' participation in the study, parents or guardians received a letter describing the research and a form to complete and return to the researchers if they did not want their child's data included in the study. The study was conducted under the guidance of the Institutional Review Board at the University of Cincinnati.

\section{Spatial skills measure}

The spatial skills instrument administered in this study was a twenty-item measure created using items from two psychometric tests of spatial skills, the Differential Aptitude Test: Space Relations (DAT:SR; Bennett, Seashore, \& Wesman, 1973) and the Purdue Spatial Visualization Test: Rotations (PSVT:R; Guay, 1977). The DAT:SR is a subtest of the Differential Aptitude Test (DAT), a test of cognitive abilities standardized in the USA with students 13 to 18 years of age (Lynn, 1992). The ten problems from the DAT:SR assessed students' skills in mental folding by requiring participants to view a 2D figure with various identifying markings on multiple faces and asking participants to select the $3 \mathrm{D}$ object constructed when the $2 \mathrm{D}$ figure is folded (Bennett et al., 1973). The PSVT:R is a subtest of the Purdue Spatial Visualization Test (PSVT) - a battery of tests measuring various spatial skills. The ten problems from the PSVT:R assessed students' skills in mental rotation. For each item, participants viewed two images of an object, one in its original position and one after it was rotated. They then selected the correct pairing for an analogous set of objects rotated in the same manner as the first set. Participants had $14 \mathrm{~min}$ to complete the full 20-item spatial measure. Each correct item received one point; Cronbach's alpha for this measure was 0.67 .

\section{Other measures}

\section{Math Motivation Questionnaire (MMQ)}

The MMQ is a self-report questionnaire measuring students' motivation to learn mathematics adapted from Glynn et al.'s (2007) Science Motivation Questionnaire (SMQ). Glynn et al. (2009) created the SMQ to study students' motivation to learn science. In studying students' motivation to learn science, "researchers examine why students strive to learn science, how intensively they strive, and what beliefs, feelings, and emotions characterize them in the process" (p. 128). In this study, we adapted the SMQ to examine students' motivation to learn mathematics, or the level at which students' strive to learn the mathematical domain, by changing the word "science" to the word "math" in each of the items.
We chose the MMQ because it encompasses the breadth of motivational constructs potentially relevant to middle school students' mathematics achievement. Since no work to our knowledge has been conducted examining the link between spatial skills and mathematics motivation specifically, we did not have prior insights into which motivational factors would be related to spatial skills. Thus, we chose to use an instrument that includes multiple motivational constructs. Furthermore, the SMQ was developed for use with undergraduate students who were enrolled in non-science majors, meaning that it was developed for a general audience, similar to what would be expected in a middle school class setting.

The six constructs measured by the MMQ are intrinsically motivated math learning $(\alpha=.78)$, extrinsically motivated math learning $(\alpha=.63)$, relevance of math learning to personal goals (i.e., personal relevance; $\alpha=$ .83), responsibility for learning math (i.e., selfdetermination; $\alpha=.57$ ), confidence in learning math (i.e., self-efficacy; $\alpha=.86$ ), and anxiety about math assessment (low math anxiety; $\alpha=.73$ ). The MMQ includes 30 items $(\alpha=.90)$. For each item, participants chose a response from a 5-point scale ranging from 1 (never) to 5 (always). Completion of the questionnaire was not timed. The MMQ items and their correspondence to the motivational constructs are listed in the Appendix.

Participants' score on the MMQ was the sum of all six construct scores. Scores ranged from 30 to 150; higher scores indicate greater motivation for learning mathematics. We focused our analyses on students' total score on the MMQ because of the measure's good content and criterion validity found in previous research (Glynn et al., 2007, 2009), as well as the high reliability of the measure in our dataset $(\alpha=.90)$. The items measuring anxiety about math assessment were reverse scored, so higher scores corresponded to lower anxiety for this particular subset. Thus, we refer to this construct as low math anxiety in this paper. Prior to calculating total scores, the data were screened for incomplete assessments and item nonresponses were identified. Data from participants who responded to fewer than 20 of the 30 total items were excluded from further analysis as inferring more than a third of the responses could lead to bias in the results (e.g., Dong \& Peng, 2013; Jakobsen, Gluud, Wetterslev, \& Winkel, 2017). For the remaining participants, item nonresponses were dealt with in the following manner: construct scores were calculated by taking the average of the included responses and multiplying it by five. This method was used to avoid further loss of information due to listwise deletion and the introduction of error resulting from missing value imputation (Cheema, 2014).

Michigan Student Test for Educational Progress (M-STEP) Mathematics (Michigan Department of Education, 2017) The M-STEP mathematics subtest is one measure in a battery of standardized assessments given to all 
Michigan students near the end of the school year in grades three to eight to assess mastery of state standards (Michigan Department of Education, 2017). We examined sixth grade M-STEP mathematics subtest score to minimize the degree to which students' cognitive profiles may have changed due to academic experiences between the time of assessments. Only the overall score on the M-STEP mathematics subtest was used in our study. Sample items from the assessment are available for viewing and practice on the Michigan Department of Education website: https://www.michigan.gov/mde/0, 4615,7-140-22709_70117-350540--,00.html (Michigan Department of Education, 2019).

\section{Science Grade Point Average (GPA)}

Science GPA is a student's calculated average performance in his or her sixth-grade science class which ranges from zero to 4.33 points. Because middle school science assessments have been found to heavily rely on students' memorization of scientific information presented through lecture and in textbooks (Stern \& Ahlgren, 2002), we used science GPA as an indicator of students' academic skill level.

\section{Procedure}

Seventh grade mathematics and science teachers administered the spatial measure and the MMQ to their students at the beginning of the academic year ${ }^{2}$. Before administering the assessments, teachers read aloud a script informing students about the purpose of the testing and their protections as research participants. The teachers were asked to administer the assessments over 2 days in an order that was randomly assigned.

\section{Results}

All analyses were conducted using $\mathrm{R}$ version 3.3.2.

\section{Relations among spatial skills, math motivation, mathematics achievement, and gender}

Table 1 presents descriptive data for the four measures utilized in this study. Pearson's correlations between all measures and gender are presented in Table 2. Following Cohen's (1988) conventions, students' spatial skills were weakly correlated with their MMQ score and their science GPA and strongly correlated with their M-STEP mathematics subtest performance. Additionally, students' M-STEP mathematics subtest performance was moderately correlated with students' MMQ score and strongly correlated with students' science GPA. Lastly,

\footnotetext{
${ }^{2}$ In the larger study, the spatial measures and the MMQ were administered twice during the school year (once at the beginning of the school year and again at the end of the school year). Because multiple exposures to an assessment can influence student response or performance (e.g., Richland, Kornell, \& Kao, 2009), only data collected during the first wave of testing were examined in this paper.
}

Table 1 Descriptive statistics for spatial measure, M-STEP mathematics subtest, science GPA, and MMQ

\begin{tabular}{llllllll}
\hline Variable & $M$ & SD & skewness & kurtosis & $\min$ & $\max$ & $n$ \\
\hline Spatial skills & 7.72 & 3.40 & 0.66 & 2.84 & 2 & 19 & 1056 \\
MMQ & 102.76 & 17.04 & -0.27 & 2.98 & 42 & 143 & 1056 \\
M-STEP & 1590.81 & 21.91 & -0.22 & 3.14 & 1518 & 1650 & 1056 \\
Science GPA & 2.97 & 1.02 & -0.96 & 3.19 & 0 & 4.33 & 1048 \\
\hline
\end{tabular}

M-STEP M-STEP mathematics subtest score, min minimum score, max maximum score

students' gender was weakly correlated with their spatial skills and their MMQ score. There was also a weak correlation between students' gender and their science GPA. Gender was not significantly correlated with students' M-STEP mathematics subtest performance.

As gender differences are apparent on many tests of spatial skills (Miller \& Halpern, 2014) and also on many motivational constructs relevant to mathematics learning during adolescence (Jacobs et al., 2002), $t$ tests were conducted to examine for gender differences on the measures conducted in this study. Analyses revealed that males outperformed females on the test of spatial skills $(t=3.05, p$ $<.01)$ and the MMQ $(t=2.09, p=.04)$. Females showed a higher science GPA than males $(t=-3.54, p<.001)$, but there were no gender differences on the M-STEP mathematics subtest $(t=0.45, p=.65)$. Results from these analyses and the descriptive statistics for each measure broken down by gender are provided in Table 3 .

\section{Hierarchical linear models examining explanatory factors of mathematics achievement}

Using the "Imer4" and "ImerTest" R packages, hierarchical linear models (HLMs), which account for the nesting of students within classrooms, were conducted to explore how students' spatial skills and motivational factors combine to predict mathematics achievement. We did not group-mean center the students' scores on each of the measures for our HLM analyses because the intercept by itself is meaningful. The intercept can be interpreted as the expected mathematics achievement for a student in a specific classroom in the absence of influence from spatial skills or from motivational factors (see Paccagnella, 2006). To account for variance attributed by students' ability to perform well academically, we controlled for science GPA in all models.

Models 1 and 2, shown in Table 4, examined how students' spatial skills and mathematics motivation individually contribute to predicting performance on the M-STEP mathematics subtest. Additionally, as prior work suggests that spatial skills and motivational factors combine differently to predict mathematics achievement in girls versus boys (Ganley \& Vasilyeva, 2011), and because we found gender differences in spatial skills and MMQ scores in our study, we examined whether gender was a moderating 
Table 2 Correlational data among all examined variables

\begin{tabular}{lllll}
\hline Variable & 1 & 2 & 3 & 4 \\
\hline 1. Spatial skills & & & & \\
2. MMQ & $0.19^{* * *}$ & & & \\
3. M-STEP & $0.50^{* * *}$ & $0.34^{* * *}$ & & \\
4. Science GPA & $0.26^{* * *}$ & $0.34^{* * *}$ & $0.57^{* * *}$ & \\
5. Gender & $-0.09^{* *}$ & $-0.06^{*}$ & -0.01 & $0.11^{* * *}$ \\
\hline
\end{tabular}

M-STEP M-STEP mathematics subtest score

${ }^{*} p<.05,{ }^{* *} p<.01,{ }^{* * *} p<.001$

variable in both models. Analyses revealed that after controlling for science GPA, spatial skills (model 1) and MMQ score (model 2) each individually significantly predict students' performance on the M-STEP mathematics subtest $(p s<.001)$. Furthermore, we found that gender does not significantly moderate the effect of spatial skills (model 1) or mathematics motivation (model 2) on students' M-STEP mathematics subtest performance, $n$.s.

To see whether students' spatial skills interacted with mathematics motivation to predict M-STEP mathematics subtest performance, we compared the results of two additional HLMs, models 3 and 4 shown in Table 5. Because we did not find gender to be a significant moderator of spatial skills or MMQ score on students' M-STEP mathematics subtest score in models 1 or 2, gender was changed from a moderator to a covariate in models 3 and 4 . Covarying for gender would allow us to examine the relations between spatial skills and mathematics motivation on students' mathematics achievement while still accounting for the variance contributed by gender differences in spatial skills or mathematics motivation. In model 3 , we included spatial skills and MMQ score as independent factors in the same model and found that spatial skills and MMQ score independently contribute to predicting students' M-STEP mathematics subtest performance, $p s<$ .001. In model 4 , we included a centered interaction term between spatial skills and MMQ score in the model. Analyses revealed a significant effect of spatial skills, a significant effect of MMQ score, and a significant interaction between spatial skills and MMQ score on students' $M$ STEP mathematics subtest performance, $p \mathrm{~s}<.05$. Lastly,

Table 3 Results of $t$ tests examining for gender differences across all measures

\begin{tabular}{llllllll}
\hline & \multicolumn{2}{l}{ Males } & & & \multicolumn{2}{l}{ Females } & \\
\cline { 2 - 3 } Measure & $M$ & $S D$ & & $M$ & SD & & $t$ \\
\hline Spatial skills & 8.033 & 3.59 & & 7.40 & 3.17 & $3.05^{* *}$ \\
MMQ & 103.85 & 17.51 & & 101.66 & 16.51 & $2.09^{*}$ \\
M-STEP & 1591.11 & 22.79 & & 1590.50 & 21.00 & 0.45 \\
Science GPA & 2.86 & 1.06 & & 3.08 & 0.96 & $-3.54^{* * *}$ \\
\hline
\end{tabular}

M-STEP M-STEP mathematics subtest score

${ }^{*} p<.05,{ }^{* *} p<.01,{ }^{* * *} p<.001$ an analysis of variance (ANOVA) comparing the two models revealed that model 4 has a lower Akaike Information Criteria $(\mathrm{AIC}=8639.5)$ than model $3(\mathrm{AIC}=8641.4)$, $X^{2}(1)=3.86, p=0.049$, indicating that the inclusion of an interaction term between spatial skills and mathematics motivation in the model (model 4) helps explain additional variance in students' mathematics performance compared to the model in which spatial skills and motivation were included independently (model 3).

\section{Exploratory analyses: further investigating the interaction between spatial skills and mathematics motivation}

To further investigate the interaction between spatial skills and mathematics motivation on students' mathematics achievement, a continuous by continuous interaction, simple slopes were computed. Simple slopes are the slopes of the dependent variable on the independent variable when the moderator variable is held constant at different combinations of values from very low to very high ("How Can I Explain Continuous by Continuous Interactions?", 2020). For this analysis, the dependent variable was M-STEP mathematics subtest performance, the independent variable was MMQ score, and the moderator variable was spatial skills. To conduct this analysis, we first examined the range of scores on the spatial skills measure $(\min =2, \max =19$; see Table 1$)$. Keeping this range in mind, we next computed the slope for $\mathrm{M}$ STEP mathematics subtest score on MMQ score while holding the value of the moderator variable, spatial skills, constant at values running from 3 to 18. Then, using the deltamethod command in the "msm" $\mathrm{R}$ package, we estimated the standard errors of these slopes and their 95\% confidence intervals, summarized in Table 6. A plot showing how the slope between M-STEP mathematics subtest performance and MMQ score changes with the level of spatial skills is provided in Fig. 1. To see if the slope at low levels of spatial skills (a spatial skills score of 3) was significantly different from the slope at high levels of spatial skills (a spatial skills score of 18), a Ztest was conducted. Results indicate no difference in the simple slope for students with very low spatial skills and students with very high spatial skills, $Z=1.66, p=0.96$.

In sum, after accounting for the variance contributed by students' academic skills (measured by their science GPA) and differences in performance driven by gender, spatial skills and mathematics motivation both contribute and interact to predict middle school students' mathematics achievement. However, exploratory analyses revealed that the role of mathematics motivation on students' mathematics performance does not differ depending on the levels of spatial skills. These results suggest that for all students, the mechanism underlying mathematical achievement includes both cognitive and motivational factors. 
Table 4 HLMs examining whether gender moderates the effect of spatial skills or motivation on M-STEP mathematics subtest performance ( $N=1048$ students, $N=26$ teachers)

\begin{tabular}{|c|c|c|c|c|}
\hline & \multicolumn{2}{|l|}{ Model 1} & \multicolumn{2}{|l|}{ Model 2} \\
\hline & $\bar{\beta}$ & $\mathrm{df}$ & $\bar{\beta}$ & $\mathrm{df}$ \\
\hline Intercept, $\gamma_{0 o}$ & $1544.68^{* * *}(2.40)$ & 158.26 & $1536.42^{* * *}(4.54)$ & 620.17 \\
\hline Science GPA, $Y_{10}$ & $10.27^{* * *}(0.51)$ & 1042.83 & $11.13^{* * *}(0.55)$ & 1040.97 \\
\hline Gender, $\gamma_{20}$ & $-2.58(2.30)$ & 1027.15 & $2.53^{* *}(5.97)$ & 1021.17 \\
\hline Spatial skills, $\gamma_{30}$ & $1.97^{* * *}(0.19)$ & 1035.62 & & \\
\hline Spatial skills ${ }^{*}$ gender, $\gamma_{40}$ & $0.12(0.27)$ & 1026.96 & & \\
\hline$M M Q, \gamma_{50}$ & & & $0.21^{* * *}(0.04)$ & 1024.48 \\
\hline$M M Q *$ gender, $\gamma_{60}$ & & & $-0.05(0.06)$ & 1021.30 \\
\hline
\end{tabular}

Numbers in parentheses are standard errors. Random effects are included for the overall intercept

${ }^{*} p<.05,{ }^{* *} p<.01,{ }^{* *} p<.001$

\section{Discussion}

When examining the factors that predict students' mathematics performance, students' spatial skills and motivation have largely been considered as independent contributors (e.g., Casey et al., 2001; Ramirez et al., 2013). Yet, much research suggests that cognitive skills and motivation are fundamentally linked (e.g., Ashcraft \& Kirk, 2001; Ferguson et al., 2015; Ganley \& Vasilyeva, 2011). Our findings start to reveal how middle school students' motivation for learning mathematics combines with their spatial skills to help predict mathematics performance.

Consistent with prior research, our study confirms that spatial skills are critical for mathematics performance (Casey et al., 1995; Verdine et al., 2017). Results from longitudinal studies indicate that the relation between spatial skills and mathematics increases across development (e.g., Stannard, Wolfgang, Jones, \& Phelps, 2006). Li and Geary (2013) found that first to fifth grade gains in visuospatial memory predicted fifth grade mathematics achievement; visuospatial memory was not related to first grade mathematics achievement. In our study, spatial skills measured in middle school predicted performance on a state mathematics assessment. To our knowledge, no research has examined whether spatial skills in middle school are predictive for mathematics learning in high school. Since gender differences in mathematics become more pronounced in high school (Hyde, Fennema, \& Lamon, 1990), whether spatial skills developed in middle school are fundamental to high school mathematics performance is an important question for future research.

In line with findings on motivation and mathematics learning (e.g., Hembree, 1990; Pajares \& Graham, 1999), our study found that students' motivation for learning mathematics was a significant predictor of their mathematics achievement measured in our study by students' scores on a state standardized mathematics test. The M-STEP mathematics subtest is an assessment of mathematics achievement measuring students' grade-level proficiency and their overall mathematical thinking skills. Since standardized test performance does not typically influence students' grades in school, students' motivation for performing well in their mathematics classes in school may be distinct from their motivation for performing well on the state standardized mathematical assessment. Future research should investigate how motivational factors predict different kinds of measures of mathematics achievement that influence students' course grades (e.g., homework grades or scores on

Table 5 HLMs examining whether spatial skills and motivation predict M-STEP mathematics subtest performance $(N=1048$ students, $N=26$ teachers)

\begin{tabular}{|c|c|c|c|c|}
\hline & \multicolumn{2}{|l|}{ Model 3} & \multicolumn{2}{|l|}{ Model 4} \\
\hline & $\bar{\beta}$ & df & $\bar{\beta}$ & df \\
\hline Intercept, $Y_{0 o}$ & $1531.43^{* * *}(3.32)$ & 448.80 & $1531.00^{* * *}(3.32)$ & 446.90 \\
\hline Science GPA, $Y_{10}$ & $9.55^{* * *}(0.52)$ & 1042.26 & $9.54^{* * *}(0.52)$ & 1041.23 \\
\hline Gender, $\gamma_{20}$ & $-1.19(0.92)$ & 1024.61 & $-1.20(0.92)$ & 1024.00 \\
\hline Spatial skills, $\gamma_{30}$ & $1.96^{* * *}(0.14)$ & 1038.21 & $1.91^{* * *}(0.92)$ & 1037.00 \\
\hline$M M Q, \gamma_{40}$ & $0.15^{* * *}(0.03)$ & 1030.77 & $0.15^{* * *}(0.03)$ & 1030.00 \\
\hline Spatial skills ${ }^{*} M M Q, \gamma_{50}$ & & & $0.02 *(0.01)$ & 1027.00 \\
\hline
\end{tabular}

Numbers in parentheses are standard errors. Random effects are included for the overall intercept ${ }^{*} p<.05,{ }^{* *} p<.01,{ }^{* * *} p<.001$ 
Table 6 Estimated standard errors and their 95\% confidence intervals of simple slopes examining spatial skills by motivation interaction

\begin{tabular}{lll}
\hline Spatial skills & Simple slope & $95 \% \mathrm{Cl}$ \\
\hline 3 & $0.20(0.04)$ & {$[0.12,0.28]$} \\
6 & $0.25(0.06)$ & {$[0.13,0.36]$} \\
9 & $0.30(0.08)$ & {$[0.14,0.45]$} \\
12 & $0.34(0.10)$ & {$[0.14,0.55]$} \\
15 & $0.39(0.13)$ & {$[0.14,0.64]$} \\
18 & $0.44(0.15)$ & {$[0.14,0.73]$} \\
\hline
\end{tabular}

Spatial skills denotes score on the spatial skills measure. Simple slope is the slope of the M-STEP mathematics subtest score on MMQ score when spatial skills score is held constant at different values (e.g., 3, 6, 9, 12, 15, 18).

Standard error of each slope is presented in parentheses

a classroom-based math test) versus measures of mathematics achievement that do not influence students' course grades (e.g., state standardized tests of mathematical achievement).

Prior research suggests that cognitive skills and motivation are connected (e.g., Ashcraft \& Kirk, 2001; Ferguson et al., 2015). Specifically related to mathematics learning, Ferguson et al. (2015) found that low spatial skills are a significant predictor of mathematics anxiety in adults. Consistent with these findings, our results suggest that spatial skills and students' motivation for learning mathematics interact to predict mathematics performance in middle school students. Work by Ganley and Vasilyeva (2011) indicates that the mechanism by which spatial skills and motivational factors, specifically self-efficacy and mathematics anxiety, combine to predict mathematics performance in middle school students differs by gender. Contrary to their results, we found that students' gender did not moderate the effect of spatial skills and mathematics motivation on their mathematics achievement. Furthermore, the results of our simple slope analysis suggest that the mechanism by which motivation and spatial skills combine to predict mathematics performance in middle school students does not vary depending on students' spatial skills. Even though the interaction between spatial skills and mathematics motivation on students' mathematics achievement was significant, there was no difference in the simple slope for students with very low spatial skills and students with very high spatial skills. This means that the effect of mathematics motivation on mathematics achievement in students with low levels of spatial skills was no different than the effect in students with high levels of spatial skills. The simple slope analysis may not have confirmed the interaction results previously found because the interaction between spatial skills and mathematics motivation was relatively weak $(p=.049)$. These findings indicate that spatial skills and mathematics motivation underlie mathematics achievement in all students and that other factors may be contributing to students' low versus high mathematics achievement. A question for future research includes identifying whether bolstering students' motivation to learn mathematics in conjunction with their spatial skills can improve mathematics outcomes in all students and whether it has long-term benefits. Additionally, researchers should examine whether earlier interventions aimed at improving students' mathematical motivation can curb the decline in motivation that commonly occurs during adolescence (e.g., Jacobs et al., 2002; Wigfield et al., 1991), and thus mitigate its potential negative effects on mathematical performance.

Consistent with prior studies examining gender differences in spatial skills (e.g., Miller \& Halpern, 2013) and motivation to learn mathematics (e.g., Jacobs et al., 2002), in our research, females showed lower scores than males on spatial skills and mathematics motivation. However, we found no differences between females and males in state standardized mathematics test performance. Additional analyses revealed that gender did not moderate the effect of spatial skills or motivation to learn mathematics

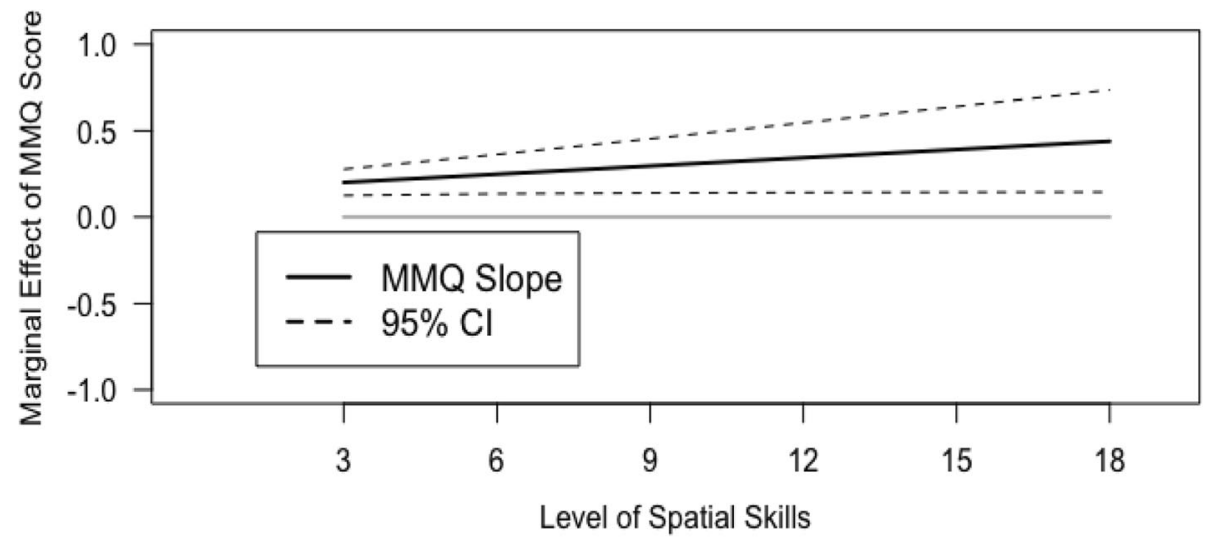

Fig. 1 Graph depicting how the slope between M-STEP mathematics subtest performance and MMQ score changes with the level of spatial skills and where the slope is significantly different from 0 
on students' mathematics achievement. These findings indicate that additional factors that we did not examine may explain the equivalent levels of mathematics achievement between females and males in our study despite the discrepancies in their spatial skills and levels of motivation. Future research should examine the role of additional cognitive variables critical to mathematics learning, such as executive functioning skills and working memory capacity (e.g., Bull \& Lee, 2014; Bull \& Scerif, 2001), in conjunction with spatial skills, motivation, and gender on students' mathematical outcomes. This research is fundamental for understanding how to improve mathematics outcomes in different kinds of students.

One limitation of our study is that students' sixth grade science GPA was the only measure of students' overall academic abilities. This could be problematic because spatial skills are important for students' science learning (e.g., Titus \& Horsman, 2009), and thus could have been a weak indicator of students' academic skills apart from spatial skills. Due to middle school science learning primarily requiring rote memorization of facts and concepts (Stern \& Ahlgren, 2002) and not science problem-solving and diagrammatic reasoning that generally utilizes spatial skills (e.g., Atit, Weisberg, Newcombe, \& Shipley, 2016), we believed that students' sixth grade science GPA would be reflective of their intellectual skills rather than their spatial skilldependent science performance. Sixth grade science GPA was weakly related to performance on the test of spatial skills $(r=.26)$. To ensure that the relations between spatial skills, motivation, and mathematics found here were not driven by students' intellectual skills, future replications should include additional measures of intellectual capacity such as measures of verbal skills or fluid reasoning.

Another limitation of our study was that the SMQ, the measure from which the MMQ was created, was originally designed for use with college students (Glynn et al., 2009). However, in our study, we employed the measure with middle school students. This may have contributed to the reliability of certain individual motivational constructs within the measure to be especially low, specifically the constructs of extrinsically motivated math learning $(\alpha=.63)$ and responsibility for learning math ( $\alpha$ $=.57$ ). Cronbach's alpha is a measure of internal consistency, an indicator of how well the items are consistent or are correlated with each other (Charter \& Feldt, 2002). As the items were originally developed for college students, and not for middle school students, some of the items within those constructs may have been inapplicable to or interpreted differently by the students in our study, resulting in lower reliability scores. We deemed this limitation as acceptable as it facilitated the use of an instrument that provided broad insight into the most commonly studied constructs within mathematics motivation. Noting that the current study sought to explore a potential additional link to mathematics motivation, spatial skills competency, we decided to use the MMQ based on its explanatory value. Future studies should focus on revising the items within these two constructs, extrinsically motived math learning and responsibility for learning math, to improve their reliability when administered to a middle school population. Additionally, replication studies should be conducted to ensure that the remaining motivational constructs in the MMQ remain reliable across different samples of participants.

Finally, there are a number of implications of the findings from this study to mathematics education and to STEM education more generally. This research highlights the need for early interventions, perhaps at the elementary level, focusing on bolstering students' motivation to learn mathematics as well as their spatial skills. Our research indicates that for all students with all levels of spatial skills, mathematics motivation contributes to their mathematics achievement. This implies that one explanation for underperforming students in mathematics may be that students with weaker spatial skills may struggle more with learning the domain than students with stronger spatial skills. As the middle grades are a critical time when it comes to a students' STEM persistence and interest (e.g., Tai et al., 2006), earlier interventions focused on improving students' spatial skills could help improve mathematics performance in underperforming students and thus potentially change their educational trajectories. Moreover, this research indicates that both spatial skills and motivational components should be incorporated into the K-12 curriculum. As prior research indicates that strong spatial skills are critical to early mathematics learning (e.g., Gunderson et al., 2012; Verdine et al., 2017), and results from our study revealed that both spatial skills and motivation to learn mathematics contribute to students' middle school mathematics outcomes, integrating both of these components into the everyday K-12 mathematics curriculum could result in long-term benefits to all students' mathematical achievement.

\section{Conclusions}

In conclusion, this study highlights the need to simultaneously account for cognitive and motivational factors in explaining mathematics performance (e.g., Cromley, Perez, \& Kaplan, 2016). In particular, our findings provide insight into how spatial skills and motivation for learning mathematics are intertwined as underlying factors of middle school students' mathematics achievement. The ability to mentally visualize and manipulate images is a cognitive skill critical for success in mathematics. At the same time, students who are motivated to succeed in mathematics are likely to show higher 
mathematics outcomes. Furthermore, our findings highlight that the role of motivation in students' mathematics achievement does not differ for students who demonstrate different levels of spatial skills. These results suggest that future interventions may have the strongest impact by targeting both the development of strong spatial skills and positive motivational factors pertinent to mathematics learning for middle school students.

\section{Supplementary information}

Supplementary information accompanies this paper at https://doi.org/10. 1186/s40594-020-00234-3.

Additional file 1. Appendix. Math Motivation Questionnaire

\section{Abbreviations}

STEM: Science, Technology, Engineering, and Mathematics;

DAT:SR: Differential Aptitude Test: Space Relations; PSVT:R: Purdue Spatial Visualization Test: Rotations; 2D: Two-dimensional; 3D: Three-dimensional; MMQ: Math Motivation Questionnaire; MSTEP: Michigan Student Test for Educational Progress; GPA: Grade point average; HLM: Hierarchical linear models; ANOVA: Analysis of variance; AIC: Akaike Information Criteria

\section{Acknowledgements}

We would like to thank all of the teachers and students who participated in this study.

\section{Authors' contributions}

KA analyzed and interpreted the data and completed the majority of the writing for the manuscript. JP and GP also helped with the writing of the manuscript. NV helped with teacher recruitment, training, and data collection for this manuscript. DU, SS, LF, and MC are the principal investigators on the grant funding this project and thus were in charge of the design and execution of the study. DU, SS, and LF also helped with the writing of this manuscript. MC sadly passed away in 2017 prior to the writing of this manuscript. CM helped to process the data for this study and helped in the writing and editing of this manuscript. The author(s) read and approved the final manuscript.

\section{Funding}

This research was supported by a grant from the US Department of Education (award number R305A150365).

\section{Availability of data and materials}

The datasets generated and analyzed for the current study are available from the corresponding author on reasonable request.

\section{Competing interests}

The authors declare they have no competing interests.

\begin{abstract}
Author details
${ }^{1}$ Graduate School of Education, University of California, Riverside, 1207 Sproul Hall, Riverside, CA 92521, USA. ${ }^{2}$ School of Education, University of Limerick, Limerick V94 T9PX, Ireland. 'Department of Engineering Fundamentals, Michigan Technological University, Houghton, Michigan, USA. ${ }^{4}$ School of Education and Social Policy, Northwestern University, Evanston, Illinois, USA ${ }^{5}$ Department of Engineering Education, University of Cincinnati, Cincinnati, Ohio, USA. ${ }^{6}$ College of Engineering, University of Nebraska - Lincoln, Lincoln, Nebraska, USA. ${ }^{7}$ Department of Educational Psychology, University of Georgia, Athens, Georgia, USA
\end{abstract}

Received: 8 November 2019 Accepted: 22 June 2020

Published online: 23 July 2020

\section{References}

Ames, C. (1992). Classrooms: Goals, structures, and student motivation. Journal of Educational Psychology, 84, 261-271.
Ames, C., \& Archer, J. (1988). Achievement goals in the classroom: Students learning strategies and motivation processes. Journal of Educational Psychology, 80, 260-267.

Andersen, L., \& Ward, T. J. (2014). Expectancy-value models for the STEM persistence plans of ninth-grade, high-ability students: A comparison between black, Hispanic, and white students. Science Education, 98(2), 216242

Ashcraft, M. H., \& Kirk, E. P. (2001). The relationships among working memory, math anxiety, and performance. Journal of Experimental Psychology: General, 130(2), 224-237. https://doi.org/10.1037/0096-3445.130.2.224.

Atit, K., Weisberg, S. M., Newcombe, N. S., \& Shipley, T. F. (2016). Learning to interpret topographic maps: Understanding layered spatial information. In Cognitive Research: Principles and Implications, 1(1). https://doi.org/https://doi. org/10.1186/s41235-016-0002-y

Bandura, A. (2001). Social cognitive theory: An agentive perspective. Annual Review of Psychology, 52, 1-26. https://doi.org/10.1146/annurev.psych.52.1.1.

Bandura, A. (2005). Evolution of social cognitive theory. In K. G. Smith \& M. A. Hitt (Eds.), Great minds in management (pp. 9-35). Oxford: Oxford University Press.

Bandura, A. (2006). Going global with social cognitive theory: From prospect to paydirt. In S. I. Donaldson, D. E. Berger, \& K. Pezdek (Eds.), The rise of applied psychology: New Frontiers and rewarding careers (pp. 53-70). Mahwah, NJ: Erlbaum.

Bandura, A. (2012). On the functional properties of perceived self-efficacy revisited. Journal of Management, 38(1), 9-44.

Beilock, S. L., \& Carr, T. H. (2005). When high-powered people fail: Working memory and "choking under pressure" in math. Psychological Science, 16(2), $101-105$.

Bennett, G. K., Seashore, H. G., \& Wesman, A. G. (1973). Differential Aptitude Tests, Forms $S$ and T. New York: Russell Sage Foundation.

Berger, J.-L., \& Karabenick, S. A. (2011). Motivation and students' use of learning strategies: Evidence of unidirectional effects in mathematics classrooms. Learning and Instruction, 21(3), 416-428.

Brophy, J. E. (1988). On motivating students. In D. Berliner \& B. Rosenshine (Eds.), Talks to teachers (pp. 201-245). New York: Random House.

Bull, R., \& Lee, K. (2014). Executive functioning and mathematics achievement Child Development Perspectives, 8(1), 36-41.

Bull, R., \& Scerif, G. (2001). Executive functioning as a predictor of children's mathematics ability: Inhibition, switching, and working memory. Developmental Neuropsychology, 19(3), 273-293.

Bulunuz, M.. \& Jarrett, O. S. (2010). Developing an interest in science: Background experiences of preservice elementary teachers. International Journal of Environmental and Science Education, 5(1), 65-84.

Casey, B. M., Lombardi, C. M., Pollock, A., Fineman, B., \& Pezaris, E. (2017). Girls' spatial skills and arithmetic strategies in first grade as predictors of fifth-grade analytical math reasoning. Journal of Cognition and Development: Official Journal of the Cognitive Development Society, 18(5), 530-555.

Casey, M. B., Nuttall, R., Pezaris, E., \& Benbow, C. P. (1995). The influence of spatial ability on gender differences in mathematics college entrance test scores across diverse samples. Developmental Psychology, 31(4), 697-705. https://doi. org/10.1037/0012-1649.31.4.697

Casey, M. B., Nuttall, R. L., \& Pezaris, E. (2001). Spatial-mechanical reasoning skills versus mathematics self-confidence as mediators of gender differences on mathematics subtests using cross-national gender-based items. Journal for Research in Mathematics Education, 32(1), 28-57. https://doi.org/10.2307/ 749620.

Chang, H., \& Beilock, S. L. (2016). The math anxiety-math performance link and its relation to individual and environmental factors: A review of current behavioral and psychological research. Current Opinion in Behavioral Sciences, 10, 33-38.

Charter, R. A., \& Feldt, L. S. (2002). The importance of reliability as it relates to true score confidence intervals. Measurement and Evaluation in Counseling, 35(2), 104-112.

Cheema, J. R. (2014). A review of missing data handling methods in education research. Review of Educational Research, 84(4), 487-508. https://doi.org/10. 3102/0034654314532697

Cleary, T. J., \& Chen, P. P. (2009). Self-regulation, motivation, and math achievement in middle school: Variations across grade level and math context. Journal of School Psychology, 47(5), 291-314. https://doi.org/10.1016/ j.jsp.2009.04.002.

Cohen, J. (1988). Statistical power analysis for the behavioral sciences (1st ed.). New York: Academic Press. 
Collins, J. L. (1982). Self-efficacy and ability in achievement behavior. New York: Paper presented at the Annual Meeting of the American Educational Research Association.

Cromley, J. G., Perez, T., \& Kaplan, A. (2016). Undergraduate STEM achievement and retention: Cognitive, motivation, and institutional factors and solutions. Policy Insights From the Behavioral and Brain Sciences, 3(1), 4-11. https://doi. org/10.1177/2372732215622648.

Delgado, A. R., \& Prieto, G. (2004). Cognitive mediators and sex-related differences in mathematics. Intelligence, 32, 25-32. https://doi.org/10.1016/S01602896(03)00061-8

Dickinson, D. J., \& Butt, J. A. (1989). The effects of success and failure on the ontask behavior of high-achieving students. Education and Treatment of Children, 12, 243-252.

Dong, Y., \& Peng, C. Y. (2013). Principled missing data methods for researchers. Springerplus, 2(1), 222

Duda, J. L., \& Nicholls, J. G. (1992). Dimensions of achievement motivation in schoolwork and sport. Journal of Educational Psychology, 84, 290-299.

Eccles, J., \& Wigfield, A. (1985). Teacher expectations and student motivation. Teacher Expectancies, 185-226.

Eccles, J. S., \& Wigfield, A. (1995). In the mind of the actor: The structure of adolescents' achievement task values and expectancy-related beliefs. Personality \& Social Psychology Bulletin, 21(3), 215-225.

Ferguson, A. M., Maloney, E. A., Fugelsang, J., \& Risko, E. F. (2015). On the relation between math and spatial ability: The case of math anxiety. Learning and Individual Differences, 39, 1-12. https://doi.org/10.1177/2372732215601438.

Ganley, C. M., \& Vasilyeva, M. (2011). Sex differences in the relation between math performance, spatial skills, and attitudes. Journal of Applied Developmental Psychology, 32(4), 235-242. https://doi.org/10.1016/j.appdev.2011.04.001.

Geary, D. C., Hoard, M. K., Byrd-Craven, J., Nugent, L., \& Numtee, C. (2007). Cognitive mechanisms underlying achievement deficits in children with mathematical learning disability. Child Development, 78(4), 1343-1359. https:// doi.org/10.1111/j.1467-8624.2007.01069.x.

Geer, E. A., Quinn, J. M., \& Ganley, C. M. (2019). Relations between spatial skills and math performance in elementary school children: A longitudinal investigation. Developmental Psychology, 55(3), 637-652.

Glynn, S. M., Taasoobshirazi, G., \& Brickman, P. (2007). Nonscience majors learning science: A theoretical model of motivation. Journal of Research in Science Teaching, 44(8), 1088-1107. https://doi.org/10.1002/tea.20181.

Glynn, S. M., Taasoobshirazi, G., \& Brickman, P. (2009). Science motivation questionnaire: Construct validation with nonscience majors. Journal of Research in Science Teaching, 46(2), 127-146.

Guay, R. B. (1977). Purdue spatial visualization test: Rotations. West Lafayette, IN: Purdue Research Foundation.

Gunderson, E. A., Ramirez, G., Beilock, S. L., \& Levine, S. C. (2012). The relation between spatial skill and early number knowledge: The role of the linear number line. Developmental Psychology, 48(5), 1229-1241. https://doi.org/10 1037/a0027433.

Harmer, A. J., \& Columba, L. (2010). Engaging middle school students in nanoscale science, nanotechnology, and electron microscopy. Journal of Nano Education, 2(1-2), 91-101.

Hembree, R. (1990). The nature, effects, and relief of mathematics anxiety. Journal of Research in Mathematics Education, 21(1), 33-46. https://doi.org/10.2307/749455.

How Can I Explain A Continuous by Continuous Interaction? (2020) UCLA: Statistical Consulting Group. Retrieved from stats.idre.ucla.edu/r/faq/how-cani-explain-a-continuous-interaction/

Hubbard, E. M., Piazza, M., Pinel, P., \& Dehaene, S. (2005). Interactions between number and space in parietal cortex. Nature Reviews, 6, 435-448. https://doi. org/10.1038/nrn1684.

Hyde, J. S., Fennema, E., \& Lamon, S. J. (1990). Gender differences in mathematics performance: A meta-analysis. Psychological Bulletin, 107(2), 139-155. https:// doi.org/10.1037/0033-2909.107.2.139.

Jacobs, J. E., Lanza, S., Osgood, D. W., Eccles, J. S., \& Wigfield, A. (2002). Changes in children's self-competence and values: Gender and domain differences across grades one through twelve. Child Development, 73(2), 509-527.

Jakobsen, J. C., Gluud, C., Wetterslev, J., \& Winkel, P. (2017). When and how should multiple imputation be used for handling missing data in randomized clinical trials - a practical guide with flowcharts. BMC Medical Research Methodology, 17.

Keys, T. D., Conley, A. M., Duncan, G. J., \& Domina, T. (2012). The role of goal orientations for adolescent mathematics achievement. Contemporary Educational Psychology, 37(1), 47-54.
Kloosterman, P. (1993, April). Students' views of knowing and learning mathematics: Implications for motivation. Paper presented at the annual meeting of the American Educational Research Association. GA: Atlanta.

Kloosterman, P., \& Gorman, J. (1990). Building motivation in the elementary mathematics classroom. School Science and Mathematics, 90, 375-382

Kyttala, M., Aunio, P., Lehto, J. E., Van Luit, J., \& Hautamaki, J. (2003). Visuospatial working memory and early numeracy. Educational and Child Psychology, 20, 65-76. https://doi.org/10.1177/1053815113477205.

Leaper, C., Farkas, T., \& Brown, C. S. (2012). Adolescent girls' experiences and gender-related beliefs in relation to their motivation in math/science and English. Journal of Youth and Adolescence, 41(3), 268-282. https://doi.org/10. 1007/s10964-011-9693-z.

Lee, J. (2009). Universals and specifics of math self-concept, math self-efficacy, and math anxiety across 41 PISA 2003 participating countries. Learning and Individual Differences, 19(3), 355-365. doi:https://doi.org/https://doi.org/10. 1016/j.lindif.2008.10.009

Li, Y., \& Geary, D. C. (2013). Developmental gains in visuospatial memory predict gains in mathematics achievement. PLoS One, 8(7), 1-9. https://doi.org/10. 1371/journal.pone.0070160.

Lombardi, C. M., Casey, B. M., Pezaris, E., Shadmehr, M., \& Jong, M. (2019). Longitudinal analysis of associations between 3-D mental rotation and mathematics reasoning skills during middle school: Across and within genders. Journal of Cognition and Development, 20(4), 487-509.

Lynn, R. (1992). Sex differences on the differential aptitude test in British and American adolescents. Educational Psychology, 12(2), 101-102. https://doi.org/ 10.1080/0144341920120201

Meece, J. L., Blumenfeld, P. C., \& Hoyle, R. H. (1988). Students' goal orientations and cognitive engagement in classroom activities. Journal of Educational Psychology, 80, 524-523.

Meyer, M. R., \& Fennema, E. (1985). Predicting mathematics achievement for females and males from causal attributions. In S. K. Damarin \& M. Shelton (Eds.), Proceedings of the seventh annual meeting of the north American chapter of the International Group for the Psychology of mathematics education (pp. 201-206). Columbus, OH: Authors.

Michigan Department of Education (2017). Michigan Student Test of Educational Progress. Retrieved from http://www.michigan.gov/mde/0,4615,7-140-22709_ 70117\%2D\%2D-,00.html.

Michigan Department of Education (2019). Online Practice for M-STEP ELA, Math, Science, and Social Studies. Retrieved from https://www.michigan.gov/mde/ 0,4615,7-140-22709_70117-350540\%2D\%2D,00.html

Middleton, J. A. (1993). An analysis of congruence of teachers' and students' personal constructs regarding intrinsic motivation in the mathematics classroom (doctoral dissertation, University of Wisconsin-Madison, 1992). Dissertation Abstracts International, 53, 3150A.

Middleton, J. A., \& Spanias, P. A. (1999). Motivation for achievement in mathematics: Findings, generalizations, and criticisms of the research. Journal for Research in Mathematics Education, 30(1), 65-88.

Miller, D. I., \& Halpern, D. F. (2013). Can spatial training improve long-term outcomes for gifted STEM undergraduates? Learning and Individual Differences. Retrieved from https://www.sciencedirect.com/science/article/pii/ S1041608012000386.

Mix, K. S. (2019). Why are spatial skill and mathematics related? Child Development Perspectives, O(0). doi:https://doi.org/10.1111/cdep.12323

Mix, K. S., \& Cheng, Y. L. (2012). The relation between space and math: Developmental and educational implications. In J. B. Benson (Ed.), Advances in Child Development and Behavior (vol. 42, pp.197-243) (Academic Press). Waltham, MA. https://doi.org/10.1016/B978-0-12-394388$0.00006-X$

Mix, K. S., Levine, S. C., Cheng, Y.-L., Young, C., Hambrick, D. Z., Ping, R., \& Konstantopoulos, S. (2016). Separate but correlated: The latent structure of space and mathematics across development. Journal of Experimental Psychology: General, 145(9), 1206-1227.

Mix, K. S., Levine, S. C., Cheng, Y.-L., Young, C. J., Hambrick, D. Z., \& Konstantopoulos, S. (2017). The latent structure of spatial skills and mathematics: A replication of the two-factor model. Journal of Cognition and Development: Official Journal of the Cognitive Development Society, 18(4), 465-492.

Newcombe, N. S., \& Shipley, T. F. (2015). Thinking about spatial thinking: New typology, new assessments. Studying Visual and Spatial Reasoning for Design Creativity, 179-192

OECD. (2016). PISA 2015: Results (volume 1). Paris, France: OECD Publishing. 
Paccagnella, O. (2006). Centering or not centering in multilevel models? The role of the group mean and the assessment of group effects. Evaluation Review, 30(1), 66-85. https://doi.org/https://doi.org/10.1177/0193841X05275649

Pajares, F. (1996). Self-efficacy beliefs in academic settings. Review of Educational Research, 66(4), 543-578

Pajares, F., \& Graham, L. (1999). Self-efficacy, motivation constructs, and mathematics performance of entering middle school students. Contemporary Educational Psychology, 24(2), 124-139. https://doi.org/10.1006/ceps.1998. 0991.

Pintrich, P. R. (2000). Multiple goals, multiple pathways: The role of goal orientation in learning and achievement. Journal of Educational Psychology, 92(3), 544.

Power, J., Lynch, R., \& McGarr, O. (2020). Difficulty and self-efficacy: An exploratory study. British Journal of Educational Technology, 51(1), 281-296.

Ramirez, G., Gunderson, E. A., Levine, S. C., \& Beilock, S. L. (2013). Math anxiety, working memory, and math achievement in early elementary school. Journal of Cognition and Development, 14(2), 187-202. https://doi.org/10.3389/fpsyg. 2016.00042.

Reuhkala, M. (2001). Mathematical skills in ninth-graders: Relationship with visuospatial abilities and working memory. Educational Psychology, 21(4), 387-399. https://doi.org/10.1080/01443410120090786.

Richardson, F. C., \& Suinn, R. M. (1972). The mathematics anxiety rating scale: Psychometric data. Journal of Counseling Psychology, 19(6), 551-554.

Richland, L. E., Kornell, N., \& Kao, L. S. (2009). The pretesting effect: Do unsuccessful retrieval attempts enhance learning? Journal of Experimental Psychology: Applied, 15(3), 243-257. https://doi.org/10.1037/0022-0663.95.2. 375.

Ryan, R. M., \& Deci, E. L. (2000). Self-determination theory and the facilitation of intrinsic motivation, social development, and well-being. American Psychologist, 55(1), 68-78. https://doi.org/10.1037/0003-066X.55.1.68.

Schunk, D. H. (2001). Social cognitive theory and self-regulated learning. In B. J. Zimmerman \& D. H. Schunk (Eds.), Self-regulated learning and academic achievement: Theoretical perspectives (2nd ed., pp. 121-151). Mahwah, NJ: Erlbaum. https://doi.org/10.1007/978-1-4612-3618-4_4.

Stannard, L., Wolfgang, C. H., Jones, I., \& Phelps, P. (2006). A longitudinal study of the predictive relations among construction play and mathematical achievement. Early Child Development and Care, 167(1), 115-125. https://doi. org/10.1080/0300443011670110.

Stansfield, W. J. (2011). Educational curriculum standards \& standardized educational tests: Comparing apples \& oranges? The American Biology Teacher, 73(7), 389-393. https://doi.org/10.1525/abt.2011.73.7.4.

Stern, L., \& Ahlgren, A. (2002). Analysis of students' assessments in middle school curriculum materials: Aiming precisely at benchmarks and standards. Journal of Research in Science Teaching, 39(9), 889-910. https://doi.org/10.1002/tea. 10050.

Tai, R. H., Liu, C. Q., Maltese, A. V., \& Fan, X. (2006). Planning early for careers in science. Science, 312(5777), 1143-1144.

Titus, S., \& Horsman, E. (2009). Characterizing and improving spatial visualization skills. Journal of Geoscience Education, 57(4), 242-254.

Uttal, D. H., Meadow, N. G., Tipton, E., Hand, L. L., Alden, A. R., Warren, C., \& Newcombe, N. S. (2013). The malleability of spatial skills: A meta-analysis of training studies. Psychological Bulletin, 139(2), 352-402. https://doi.org/https:// doi.org/10.1037/a0028446

Uttal, D. H., Scudder, K. V., \& DeLoache, J. S. (1997). Manipulatives as symbols: A new perspective on the use of concrete objects to teach mathematics. Journal of Applied Developmental Psychology, 18(1), 37-54 https://sites. northwestern.edu/uttallab/files/2015/08/uttaletal1997-2cauaa0.pdf.

Verdine, B. N., Golinkoff, R. M., Hirsch-Pasek, K., \& Newcombe, N. S. (2017). Links between spatial and mathematical skills across the preschool years. Monographs of the Society for Research in Child Development, 82(1), 1-150.

Wang, Z., Shakeshaft, N., Schofield, K., \& Malanchini, M. (2018). Anxiety is not enough to drive me away: A latent profile analysis on math anxiety and math motivation. PLoS One, 13(2).

Wigfield, A., \& Eccles, J. S. (2000). Expectancy-value theory of achievement motivation. Contemporary Educational Psychology, 25(1), 68-81.

Wigfield, A., Eccles, J. S., Mac Iver, D., Reuman, D. A., \& Midgley, C. (1991). Transitions during early adolescence: Changes in children's domain-specific self-perceptions and general self-esteem across the transition to junior high school. Developmental Psychology, 27(4), 552-565.

Zhang, X., Koponen, T., Rasanen, P., Aunola, K., Lerkkanen, M., \& Nurmi, J. (2014). Linguistic and spatial skills predict early arithmetic development via counting sequence knowledge. Child Development, 85(3), 1091-1107. https://doi.org/ 10.1111/cdev.12173.

\section{Publisher's Note}

Springer Nature remains neutral with regard to jurisdictional claims in published maps and institutional affiliations.

\section{Submit your manuscript to a SpringerOpen ${ }^{\circ}$ journal and benefit from:}

- Convenient online submission

- Rigorous peer review

- Open access: articles freely available online

High visibility within the field

- Retaining the copyright to your article

Submit your next manuscript at $\boldsymbol{\sim}$ springeropen.com 